\title{
Increasing Leaf Vein Density via Mutagenesis in Rice Results in an Enhanced Rate of Photosynthesis, Smaller Cell Sizes and Can Reduce Interveinal Mesophyll Cell Number
}

\section{OPEN ACCESS}

Edited by:

Apichart Vanavichit,

Kasetsart University, Thailand

Reviewed by:

Baltazar Antonio,

National Agriculture and Food Research Organization (NARO), Japan Robert Spencer Caine, University of Sheffield, United Kingdom

*Correspondence:

Aryo B. Feldman

aryofeldman@gmail.com

Specialty section: This article was submitted to Plant Genetics and Genomics,

a section of the journal

Frontiers in Plant Science

Received: 18 April 2017

Accepted: 17 October 2017

Published: 01 November 2017

Citation:

Feldman AB, Leung $H$, Baraoidan $M$, Elmido-Mabilangan A, Canicosa I, Quick WP, Sheehy J and Murchie EH (2017) Increasing Leaf Vein Density via Mutagenesis in Rice Results in an Enhanced Rate of Photosynthesis, Smaller Cell Sizes and Can Reduce Interveinal Mesophyll Cell Number. Front. Plant Sci. 8:1883. doi: 10.3389/fpls.2017.01883
Aryo B. Feldman ${ }^{*}$, Hei Leung ${ }^{2}$, Marietta Baraoidan², Abigail Elmido-Mabilangan ${ }^{3}$, Irma Canicosa ${ }^{3}$, William P. Quick ${ }^{3,4}$, John Sheehy ${ }^{3}$ and Erik H. Murchie ${ }^{5}$

${ }^{1}$ Crops for the Future, Semenyih, Malaysia, ${ }^{2}$ Plant Breeding, Genetics and Biotechnology, The International Rice Research Institute, Los Baños, Philippines, ${ }^{3}$ The $C_{4}$ Rice Center, The International Rice Research Institute, Los Baños, Philippines, ${ }^{4}$ Department of Animal Plant Sciences, University of Sheffield, Sheffield, United Kingdom, ${ }^{5}$ Division of Plant and Crop Sciences, School of Biosciences, University of Nottingham, Sutton Bonington, United Kingdom

Improvements to leaf photosynthetic rates of crops can be achieved by targeted manipulation of individual component processes, such as the activity and properties of RuBisCO or photoprotection. This study shows that simple forward genetic screens of mutant populations can also be used to rapidly generate photosynthesis variants that are useful for breeding. Increasing leaf vein density (concentration of vascular tissue per unit leaf area) has important implications for plant hydraulic properties and assimilate transport. It was an important step to improving photosynthetic rates in the evolution of both $\mathrm{C}_{3}$ and $\mathrm{C}_{4}$ species and is a foundation or prerequisite trait for $\mathrm{C}_{4}$ engineering in crops like rice (Oryza sativa). A previous high throughput screen identified five mutant rice lines (cv. IR64) with increased vein densities and associated narrower leaf widths (Feldman et al., 2014). Here, these high vein density rice variants were analyzed for properties related to photosynthesis. Two lines were identified as having significantly reduced mesophyll to bundle sheath cell number ratios. All five lines had 20\% higher light saturated photosynthetic capacity per unit leaf area, higher maximum carboxylation rates, dark respiration rates and electron transport capacities. This was associated with no significant differences in leaf thickness, stomatal conductance or $\mathrm{CO}_{2}$ compensation point between mutants and the wild-type. The enhanced photosynthetic rate in these lines may be a result of increased RuBisCO and electron transport component amount and/or activity and/or enhanced transport of photoassimilates. We conclude that high vein density (associated with altered mesophyll cell length and number) is a trait that may confer increased photosynthetic efficiency without increased transpiration.

Keywords: photosynthesis, leaf anatomy, venation, mutation breeding, rice

Abbreviations: $\mathrm{A}, \mathrm{CO}_{2}$ assimilation rate; $\mathrm{BC}_{1} \mathrm{~F}_{2}$, second filial generation after one backcross; $\mathrm{BSC}$, bundle sheath cell; $\mathrm{C}_{\mathrm{i}}$, intercellular $\mathrm{CO}_{2}$ concentrations; $\mathrm{CO}_{2} \mathrm{R}, \mathrm{CO}_{2}$ reference; $\mathrm{CP}$, compensation point; $\mathrm{E}$, evapotranspiration rate; FAA, formalinacetic acid-alcohol solution; $g_{m}$, mesophyll conductance; $g_{s}$, stomatal conductance rate; IRGA, infrared gas analyzer; IRRI, the International Rice Research Institute; IVD, interveinal distance; $\mathrm{I}_{\max }$, the capacity for thylakoid electron transport; $\mathrm{M}_{1}$, first mutant generation; MC, mesophyll cell; PAR, photosynthetically active radiation; $\mathrm{QE}$, quantum efficiency; $\mathrm{R}_{\mathrm{d}}$, dark respiration; RuBisCO, ribulose bis-phosphate carboxylase/oxygenase; RuBP, ribulose-1,5-bisphosphate; SLA, specific leaf area; TPU, triose phosphate utilization; $\mathrm{Vc}_{\max }$, rate of RubisCO-catalyzed carboxylation; WUE, water use-efficiency. 


\section{INTRODUCTION}

Genetic gains in the grain yield per hectare of major crops like rice and wheat need to rise faster than the current rate in order to meet the needs of a growing global population and the negative effects of climate change (Ray et al., 2012; Challinor et al., 2014). Leaf photosynthesis has been identified as an important trait because it is an essential component of canopy radiation-use efficiency which currently operates well below the theoretical maximum (Murchie et al., 2009; Ort et al., 2015). It has been shown empirically and theoretically that an improvement in photosynthetic capacity and quantum yield will raise canopy photosynthesis, biomass and yield, especially under optimal conditions (Long et al., 2006; Mitchell and Sheehy, 2006; Murchie et al., 2009). Photosynthesis has many components that could be improved, such as Calvin Cycle activity and kinetics, and photoprotection (Murchie and Niyogi, 2011; Kromdijk et al., 2016). In the case of rice, high tropical temperatures have attracted research into the feasibility of introducing $\mathrm{C}_{4}$ mechanisms (Karki et al., 2013; Covshoff et al., 2016). However, substantial gains can also be made through altering the existing $\mathrm{C}_{3}$ pathway (Zhu et al., 2010; Ort et al., 2015).

Leaf venation is a trait that underlies several important physiological responses and provides mechanical support (Sack and Scoffoni, 2013). However, it may have been overlooked in terms of breeding. The reduced interveinal density (IVD), or high vein density, characteristic is thought to be one of the earliest steps in the evolution of $\mathrm{C}_{4}$ photosynthesis by many researchers (McKown and Dengler, 2007, 2009; Kajala et al., 2011; Christin et al., 2013). However, leaf venation also played crucial roles in terrestrial plant evolution long before the rise of $\mathrm{C}_{4}$ photosynthesis. It is key to the plant hydraulic system as water molecules move much less easily through mesophyll cells (MCs) (probably via the apoplastic pathway) compared to how they are conducted through the xylem (via tracheids and vessels) (McElrone et al., 2013). The venation system should be tightly linked to photosynthesis since $\mathrm{CO}_{2}$ enters the plant via the stomata in exchange for transpired water (around one molecule of the former for 400 molecules of the latter, McElrone et al., 2013) and because photosynthate transport away from the leaf is via the phloem. Therefore, good vascular connectivity is needed for MCs to support high photosynthesis (Brodribb et al., 2007). This would seem to justify the observation that evolutionary changes in vein density are positively correlated with higher maximum photosynthesis $\left(\mathrm{A}_{\max }\right)$ values. The three-to-four-fold increase in vein density during early angiosperm evolution has been connected to the rise in photosynthetic capacity (as well as transpiration and hydraulic efficiency) in the absence of other $\mathrm{C}_{4}$ traits (Boyce et al., 2009; Brodribb and Feild, 2010).

Leaf vein density in cereals is a readily measured trait that may provide potential for improving photosynthesis via its effects on hydraulic conductance. The relationship between plant hydraulic conductance and photosynthesis is clear as shown for rice (Taylaran et al., 2011). However, the correlation between leaf vein density and leaf hydraulic conductance is not consistently shown in the literature and recent work in the natural variation in the dicot, Arabidopsis thaliana, failed to show a relationship between photosynthesis and vein density (Nardini et al., 2003; Scoffoni et al., 2011; Rishmawi et al., 2017).

The following investigation into the phenotypes of novel rice mutant variants shows how increased leaf vein density confers beneficial photosynthetic traits that are not directly associated with the $\mathrm{C}_{4}$ condition but which may provide resources for improving $\mathrm{C}_{3}$ photosynthesis and for $\mathrm{C}_{4}$ engineering. A deeper understanding of the increased vein density trait itself and how it links to other leaf anatomy traits (Giuliani et al., 2013) to improve both $\mathrm{C}_{3}$ and $\mathrm{C}_{4}$ photosynthesis will further benefit efforts toward raising the photosynthetic capacity and efficiency of rice (and other candidate $\mathrm{C}_{3}$ crops) and so improving future agricultural production.

\section{MATERIALS AND METHODS}

\section{Plant Material}

The primary genetic resource was IRRI IR64 mutant library (consisting of 66,891 lines) that was derived from a single rice plant (Oryza sativa cv. IR64), IR64-21 (Wu et al., 2005). The mutant library, as for all IRRI seed stock, follows all the international guidelines and legislation of the International Treaty on Plant Genetic Resources for Food and Agriculture. The original IR64-21 parent plant was selected for phenotypic uniformity from breeder seeds grown under field conditions. IR64 mutants used in the screening were either deletions (mainly dry seeds mutagenized with $\gamma$-radiation at $250 \mathrm{GY}$ at the International Atomic Energy Agency) or point mutations (mainly pre-soaked seed mutagenized with EMS at 0.4, 0.6, 0.8, 1.0, and $1.6 \%$ concentrations at IRRI). Mutagenized lines were advanced every 4 months from the initial $M_{1}$ (first mutant generation) population by single seed descent until at least the $\mathrm{M}_{3}$ generation. This was to ensure near homozygous inbred lines, which was essential for quantifying phenotypic characteristics in replicated trials.

Increased vein density lines were selected using a high throughput screen (Feldman et al., 2014). Rice plants from the deletion mutant populations had their veins counted on-site using a handheld microscope (Readiview handheld microscope, Meade Instruments Corporation, Irvine, CA, United States) at 80x magnification.

\section{Leaf Anatomy}

High vein density lines from the mutant populations were subjected to detailed microscopy analysis. Vein counts per $2 \mathrm{~mm}$ and cellular arrangements were viewed with a light microscope (Olympus BX51 Motorized Research Microscope, Tokyo, Japan, connected to an Olympus DP71 Microscope Digital Camera, Tokyo, Japan). Images were taken using Olympus Cell^ ${ }^{\wedge}$ imaging software (from the Olympus Cell* software family) and had their parameters quantified using ImageJ (Version 1.44).

Vein density viewings were taken of fresh leaf samples at $4 \mathrm{x}$ magnification. Samples were then fixed in FAA (formalinacetic acid-alcohol solution) (500 ml absolute ethanol : $270 \mathrm{ml}$ formaldehyde : $50 \mathrm{ml}$ acetic acid : $180 \mathrm{ml}$ water) for at least $12 \mathrm{~h}$. These were cross-sectioned by hand using a razor blade. 


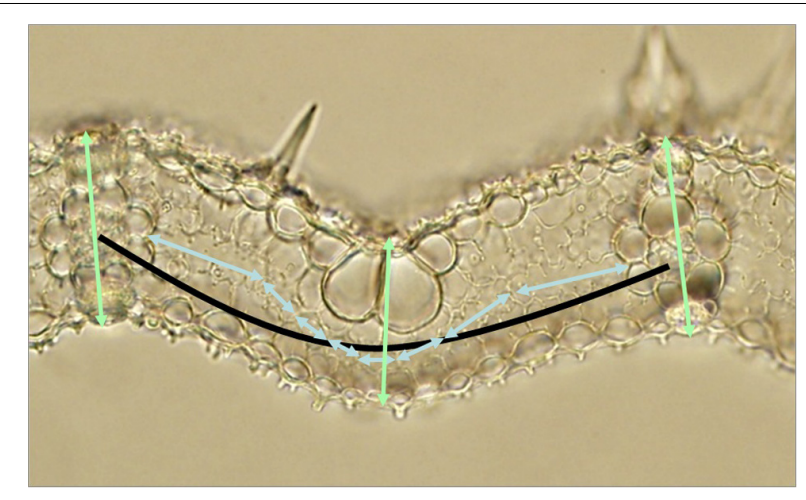

FIGURE 1 | Determining anatomical parameters in a rice leaf section. The light blue double-ended arrows represent mesophyll cell lengths (and their number equates to the mesophyll number). The light green double-ended arrows represent leaf thicknesses. The black arc represents interveinal distance. Measurements of line length were made using a calibrated microscope and image as described in "Materials and Methods".

Leaf sections were placed in $85 \%$ ethanol for $24 \mathrm{~h}$, after which the ethanol was removed and rinsed off with water. A fresh application of $85 \%$ ethanol was then applied for $24 \mathrm{~h}$. The ethanol was removed and rinsed off with water after this period and replaced by lactic acid for 30-36 h before being washed with water. At 40x magnification, MCs and BSCs could be viewed. Measurements of leaf thickness, IVDs, numbers of MCs between veins and $\mathrm{MC}$ lengths were made for leaf 5-7 of three replicate plants per line. Figure 1 illustrates how these parameters could be taken from leaf section images.

\section{Photosynthesis}

Photosynthesis measurements were performed using the portable IRGAs, LI-COR LI-6400 and LI-6400XT machines (LI-COR Environmental, Lincoln, NE, United States). A/C $\mathrm{C}_{\mathrm{i}}$ [assimilation rate $\left(\mu \mathrm{mol} \mathrm{CO} \mathrm{m}^{-2} \mathrm{~s}^{-1}\right.$ ) over intercellular $\mathrm{CO}_{2}$ concentration $\left.\left(\mu \mathrm{mol} \mathrm{mol}{ }^{-1}\right)\right]$ curves were run according to the following program: $\mathrm{CO}_{2} \mathrm{R}\left(\mathrm{CO}_{2}\right.$ reference) steps (in order) of 1800,1800 , $1600,1400,1200,1000,800,600,400,200,100,80,60,40,20$, and $1800 \mu \mathrm{mol} \mathrm{mol}^{-1}$ with $3-5 \mathrm{~min}$ waiting time, $1500 \mu \mathrm{mol}$ $\mathrm{m}^{-2} \mathrm{~s}^{-1} \mathrm{PAR}$ (photosynthetically active radiation), $400 \mu \mathrm{mol} \mathrm{s}^{-1}$ gas flow and $30^{\circ} \mathrm{C}$ block temperature. The program descended in $\mathrm{CO}_{2} \mathrm{R}$ levels for each subsequent step (besides the second and last ones) as it was found from trial testing that it took the leaf longer to adjust to increasing, as opposed to decreasing, ambient $\mathrm{CO}_{2}$ levels. The first step of $1800 \mu \mathrm{mol} \mathrm{mol}{ }^{-1}\left[\mathrm{CO}_{2} \mathrm{R}\right]$ was repeated to ensure that the leaf had enough time to stably react to the high $\left[\mathrm{CO}_{2}\right]$. The last step of $1800 \mu \mathrm{mol} \mathrm{mol}{ }^{-1}\left[\mathrm{CO}_{2} \mathrm{R}\right]$ was included to prepare the photosynthesis machine for the next round of measurements.

A/PAR [assimilation rate over incident PAR ( $\mu$ mol photons $\left.\mathrm{m}^{-2} \mathrm{~s}^{-1}\right)$ ] curves were run according to the following program: PAR steps (in order) of 2000, 1750, 1500, 1250, 1000, 750, 500, $250,100,50,20,0$, and $2000 \mu \mathrm{mol} \mathrm{m}^{-2} \mathrm{~s}^{-1}$ with $3-5 \mathrm{~min}$ waiting time, $400 \mu \mathrm{mol} \mathrm{mol}^{-1} \mathrm{CO}_{2} \mathrm{R}, 400 \mu \mathrm{mol} \mathrm{s}^{-1}$ gas flow and $30^{\circ} \mathrm{C}$ block temperature. The program descended in PAR levels for each subsequent step (besides the last one) as it was found from trial testing, that it took the leaf longer to adjust to increasing, as opposed to decreasing, levels. The last step of $2000 \mu \mathrm{mol} \mathrm{m}^{-2} \mathrm{~s}^{-1}$ PAR was included to prepare the photosynthesis machine for the next round of measurements and was not used in data analysis.

Cuvette humidity levels were always kept between 67 and $70 \%$. Plants were kept well-watered during the photosynthesis measurements to ensure that stomatal conductance was always high (stomatal conductance at ambient $\mathrm{CO}_{2}$ level was $\geq 0.4 \mathrm{~mol}$ $\left.\mathrm{m}^{-2} \mathrm{~s}^{-1}\right)$.

Three replicate measurements of the same leaf (the youngest fully expanded leaf of the main tiller) of a plant at midvegetative stage were taken using the same IRGA machine for each photosynthesis curve of each plant measured. Controlling for variation with time, rather than sibling plants per line, was found to be the most important factor and was controlled by measuring the same leaf/same plant/same line/mutant without adding variation with intra-genetic-line variation. Measurements on control wild-type plants were made in a way that effectively accounted for time, environment and developmental variation. Measurements took place between 08:30 and 14:30 under greenhouse conditions. Plants were treated with artificial lighting that was controlled to give a light intensity of $200 \mu \mathrm{mol} \mathrm{m}^{-2} \mathrm{~s}^{-1}$ when days were particularly overcast.

Photosynthetic parameters were calculated both manually and through modeling and curve fitting software (Sharkey et al., 2007). From an $\mathrm{A} / \mathrm{C}_{\mathrm{i}}$ curve, the $\mathrm{CP}\left(\mu \mathrm{mol} \mathrm{mol}^{-1}\right)$ was the $\mathrm{x}$-axis intercept of the regression line for photosynthesis rates when $C_{i}$ was $<200 \mu \mathrm{mol} \mathrm{mol}^{-1}$ (six data points). The model used was based on the Farquhar and von Caemmerer biochemical model of leaf photosynthesis and calculated the remaining parameters, i.e., $\mathrm{Vc}_{\max }$ (rate of RubisCO-catalyzed carboxylation) ( $\mu \mathrm{mol} \mathrm{m}^{-2}$ $\mathrm{s}^{-1}$ ), $\mathrm{J}_{\max }$ [the regeneration of RuBP (ribulose-1,5-bisphosphate) controlled by the rate of TPU) $\left(\mu \mathrm{mol} \mathrm{m} \mathrm{m}^{-2} \mathrm{~s}^{-1}\right.$ ], TPU (capacity of the leaf to use the primary product of the chloroplast) ( $\mu \mathrm{mol}$ $\left.\mathrm{m}^{-2} \mathrm{~s}^{-1}\right), \mathrm{g}_{\mathrm{m}}$ (mesophyll conductance) $\left(\mu \mathrm{mol} \mathrm{m}{ }^{-2} \mathrm{~s}^{-1} \mathrm{~Pa}^{-1}\right)$.

From an A/PAR curve, $\mathrm{R}_{\mathrm{d}}\left(\mu \mathrm{mol} \mathrm{CO}_{2} \mathrm{~mol}^{-1}\right.$ ) was the negative $y$-axis intercept of the regression line for photosynthesis rates when PAR was $<200 \mu \mathrm{mol} \mathrm{m}{ }^{-2} \mathrm{~s}^{-1}$ (four data points). The slope of the regression line was taken to be the maximum QE. The photosynthesis rate at saturating PAR was taken to be $A_{\max }$. Instantaneous WUE (assimilation rate divided by transpiration rate; $\mathrm{A} / \mathrm{E}$ ) and intrinsic WUE (assimilation rate divided by stomatal conductance rate; $\mathrm{A} / \mathrm{g}_{\mathrm{s}}$ ) were calculated at $\mathrm{A}_{\max }$.

\section{Growing Conditions}

Measurements took place at the IRRI greenhouses $\left(14^{\circ} 10^{\prime}\right.$ $\left.23.29^{\prime \prime}, 121^{\circ} 15^{\prime} 32.44^{\prime \prime}\right)$. Seeds were incubated at $50^{\circ} \mathrm{C}$ for $72 \mathrm{~h}$ if their dormancy had to be broken, i.e., if seeds were more than 2 years old or if germination rates were particularly poor $(<30 \%)$. They were then pre-germinated in petri dishes on filter paper treated with sterilized distilled water and incubated at $35^{\circ} \mathrm{C}$ until the radical and coleoptile was sufficiently swollen (usually by $24 \mathrm{~h}$ ). Soil was sourced from the IRRI upland farm and was treated with 0.09-0.01-0.09 $\mathrm{g}$ NPK fertilizer per $\mathrm{kg}$ soil as a basal dressing and $0.09 \mathrm{~g} \mathrm{~N}$ fertilizer per $\mathrm{kg}$ soil every 2-3 weeks, depending on plant growth rate (determined qualitatively on a 
relative scale). Irrigation was applied generously to ensure that the soil moisture content was always high.

\section{Statistical Analysis}

One way analyses of variance (ANOVAs) tested differences between categories (e.g., rice genotype) for dependent variables (e.g., vein density, leaf width and anatomical traits). Simple linear regressions tested whether two dependent variables were correlated. Regression analyses and ANOVAs were calculated using Genstat Twelfth Edition (Version 12.1.0.3278).

\section{RESULTS}

\section{Linkage of Vein Density with Leaf Width}

In a previous study, it became apparent that variants that had narrower leaf widths were more likely to have higher vein densities (Feldman et al., 2014). This led to a candidate list of narrow leaf mutants, which both segregated for the increased vein density trait close to an expected ratio (1:3 for a monogenic recessive gene) and transmitted the phenotype over successive generations.

It was clear that leaf width and vein density were also linked in $\mathrm{BC}_{1} \mathrm{~F}_{2}$ (second filial generation after one backcross) segregants of the high vein density, narrow leaf width mutant lines (Figure 2). Segregants with the wild-type leaf width phenotype predominantly had wild-type vein density phenotypes. The opposite was the case for the remaining segregants, which most often had narrow leaves and high vein densities. It can be seen in Figure 2 that the wild-type leaf width segregants had almost the same frequency distribution of vein densities as for the IR64 wildtype. This was unlike the mutant leaf width segregants, which had a distinct frequency distribution curve for vein densities that peaked at 2 veins $\mathrm{mm}^{-1}$ greater than the peak of the controls (wild-type leaf width segregants and IR64 wild-type).

Figure 3 illustrates the level of phenotypic distinction of the $\mathrm{M}_{5}$ candidate lines (Figures 3B-F) from the IR64 wildtype (Figure 3A). This phenotypic distinction was equivalent to that between mutant and wild-type segregants in the $\mathrm{BC}_{1} \mathrm{~F}_{2}$ mutant candidate lines. Though plants were qualitatively not much shorter and had similar numbers of tillers, mutants had distinctly narrow leaf sheaths in addition to narrow leaf blades. This also made their stems narrower. The degree to which mutant plants had narrower leaves is illustrated in Figure 4. Line E220971-3-1 (Figure 3C) had the widest leaves of the mutants: $9 \mathrm{~mm}$ for the widest section of the widest leaf compared to 5-6 $\mathrm{mm}$ for other mutant lines and $11 \mathrm{~mm}$ for the parental control.

The qualitative scoring of the narrow leaf trait in mutant plants was straightforward and reliable. In addition to having narrow stems and leaves, they had a darker green color (stems and leaves) and had less leaf ridges (which could be sensed both tactilely and visually) (Figure 4).

\section{Identifying Changes in the Cellular Arrangement of Leaf Anatomy}

The vein density screen was partly set up to test the hypothesis that increases in vein density would lead to changes in leaf cell structure, fundamentally in terms of decreasing interveinal MC numbers (for a low MC to BSC ratio), which is especially important to $\mathrm{C}_{4}$ photosynthesis as the two cell types perform separate functions in $\mathrm{C}_{4}$ photosynthesis.

Increased vein densities in $\mathrm{C}_{4}$ plants are the direct result of a leaf anatomy that has smaller IVDs and fewer MCs of approximately the same size, compared to $C_{3}$ plants. The link between vein density and cellular arrangement in the Oryza genus was confirmed in various rice lines (high vein density deletion mutants, non-high vein density deletion mutants, and ssp. indica and ssp. japonica wild-type cultivars) in a long-term greenhouse experiment (Supplementary Table S1). Vein density correlated negatively with IVD $(p<0.001)$ and negatively with MC number $(p<0.001)$ but did not correlate with MC length $(p>0.05)$ MC number was positively correlated with $\operatorname{IVD}(p<0.001)$ and was negatively correlated with MC length $(p<0.005)$. Finally, MC length correlated positively with IVD $(p<0.001)$. Similar trends were found in a subsequent experiment of high vein density mutants (Table 1), except that rather than vein density correlating with MC number $(p>0.05)$, it correlated negatively with MC length $(p<0.001)$.

Mutant lines in the final candidate deletion mutant population (E11068-1-10, E19076-1-5, E22097-1-3, E26181-1-1 and G55811-5) were not only distinguished by their higher vein densities and narrower leaf widths, but were also distinct in terms of cellular structure. They had smaller values of IVD and MC length compared to their parental control $(p<0.001)$ (Figure 5 and Table 1). MC counts were generally not different from the control with the exceptions of E216181-1-1-2 and G558-11-5-2, both of which had fewer MCs $(p<0.05)$.

\section{Photosynthesis}

Apart from the association with other $\mathrm{C}_{4}$ metabolic adaptations, vein density has also been linked to photosynthetic performance possibly by controlling the capacity of the hydraulic system and photosynthate transport (Brodribb et al., 2007). To help test this, photosynthetic rates of high vein density candidate mutant plants were measured at varying $\mathrm{CO}_{2}$ and light levels (Figure 6). In this way, candidate mutants could be characterized by key photosynthetic parameters that distinguish $\mathrm{C}_{4}$ from $\mathrm{C}_{3}$ species (Table 2). No $\mathrm{C}_{4}$-specific properties were found in these plants.

Figure 6 gives an overview of the $A / C_{i}$ and $A / P A R$ responses and shows that the mutant plants had higher $(p<0.001)$ photosynthesis for higher levels of incident light (PAR) and $C_{i}$ compared to the IR64 wild-type control.

Table 2 shows the results of photosynthetic analysis. From the $\mathrm{A} / \mathrm{C}_{\mathrm{i}}$ curve, $\mathrm{Vc}_{\max }$ indicates the amount of active RuBisCO present in the leaf, $\mathrm{J}_{\max }$ represents the capacity for thylakoid electron transport and TPU is an estimation of the ability to use the end-products of photosynthesis in the chloroplast. From the light response curve, $\mathrm{A}_{\max }$ is the light saturated photosynthetic capacity and $\mathrm{R}_{\mathrm{d}}$ is the rate of $\mathrm{CO}_{2}$ loss with or without light energy (i.e., respiration rate). All five parameters were increased in mutant lines $\left(p<0.05\right.$ for $\mathrm{Vc}_{\max } ; p<0.001$ for $\mathrm{J}_{\max }, \mathrm{TPU}, \mathrm{R}_{\mathrm{d}}$ and $A_{\max }$ ). Supplementary Table S2 illustrates variation between mutant lines for these parameters. 


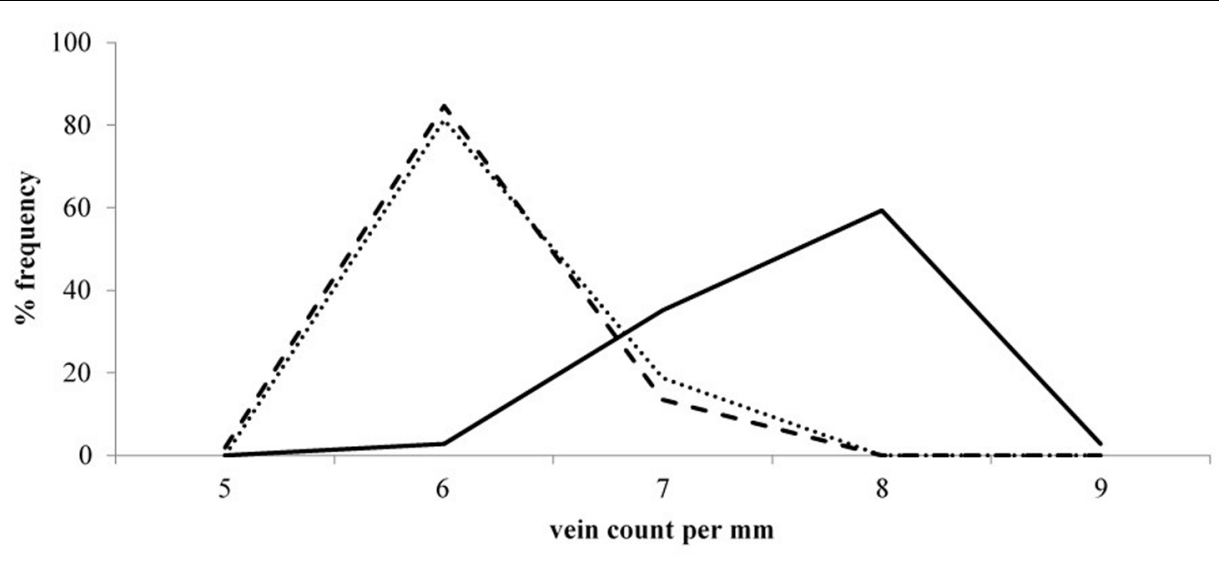

— narrow leaf width segregants

- - - wild-type leaf width segregants

IR64-21

FIGURE 2 | Vein density frequency curves for narrow and wild-type leaf width $\mathrm{BC}_{1} \mathrm{~F}_{2}$ deletion mutant segregants. $\mathrm{BC}_{1} \mathrm{~F}_{2}$ : second filial generation after one backcross. Distribution frequencies illustrate the relative number of plants for each vein density in the IR64 wild-type (dashed line), wild-type leaf width mutant segregants (dotted line) and narrow leaf width segregants (solid line).

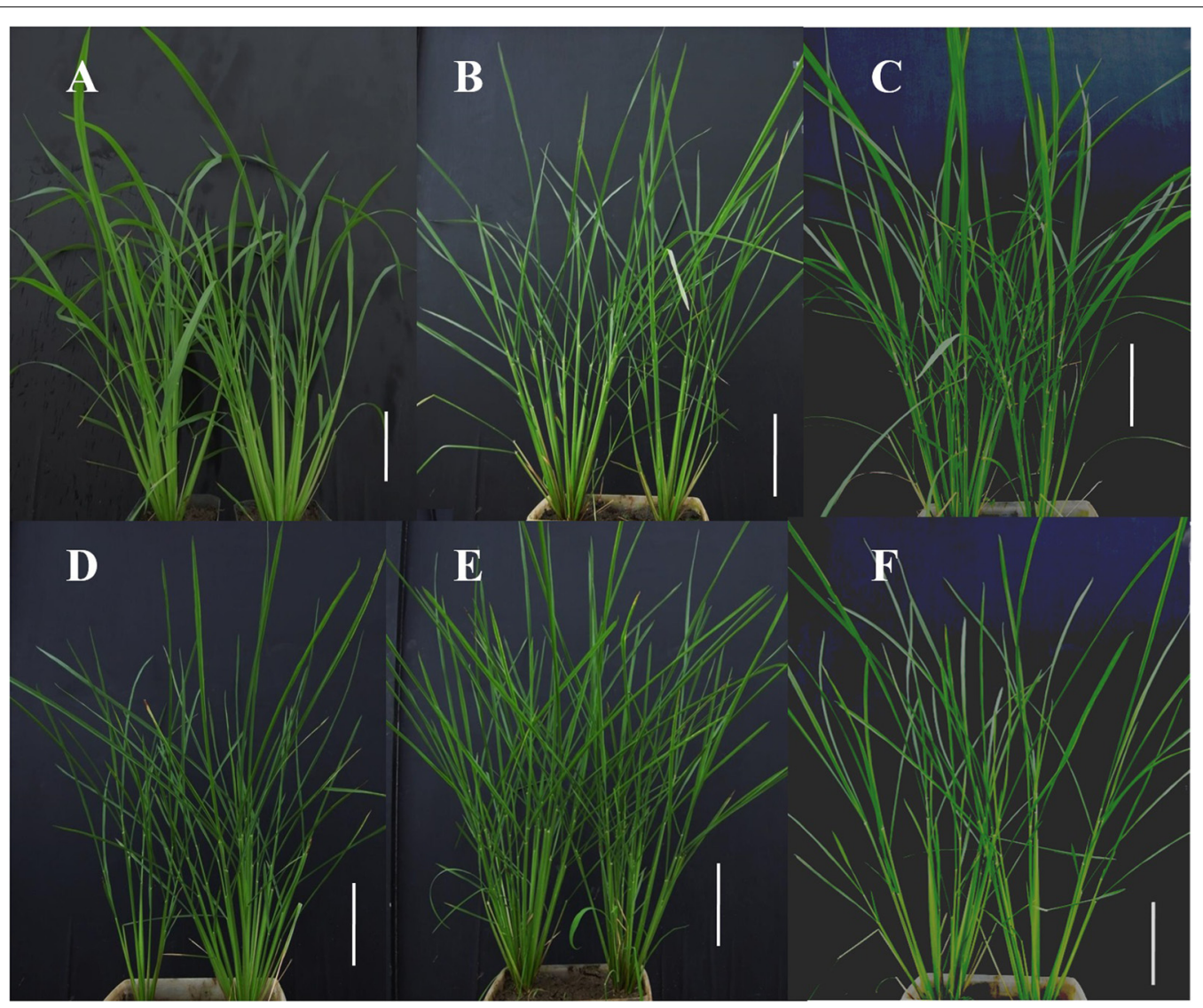

FIGURE 3 | Phenotyping images of $\mathrm{M}_{5}$ mutant progeny at the mid-vegetative stage. $\mathrm{M}_{5}$ : fifth mutant generation. White scale bar: 15 cm. (A) Wild-type IR64, \#1 and \#2. (B) E19076-1-5-3, \#1 and \#2. (C) E22097-1-3-1, \#1 and \#2. (D) E26181-1-1-2, \#1 and \#2. (E) Ell068-1-10-1, \#1 and \#2. (F) G558-11-5-2, \#1 and \#2.

A plant's leaf thickness can be correlated with photosynthetic capacity due to the accumulation of photosynthetic components per unit leaf area in $C_{3}$ plants (Peng, 2000; Marenco et al., 2009).
Additionally, thinner leaves are characteristic of $\mathrm{C}_{4}$ species where they ensure closer contact between MCs and BSCs (Dengler et al., 1994; Leegood, 2000) as well as a shorter vertical distance between 


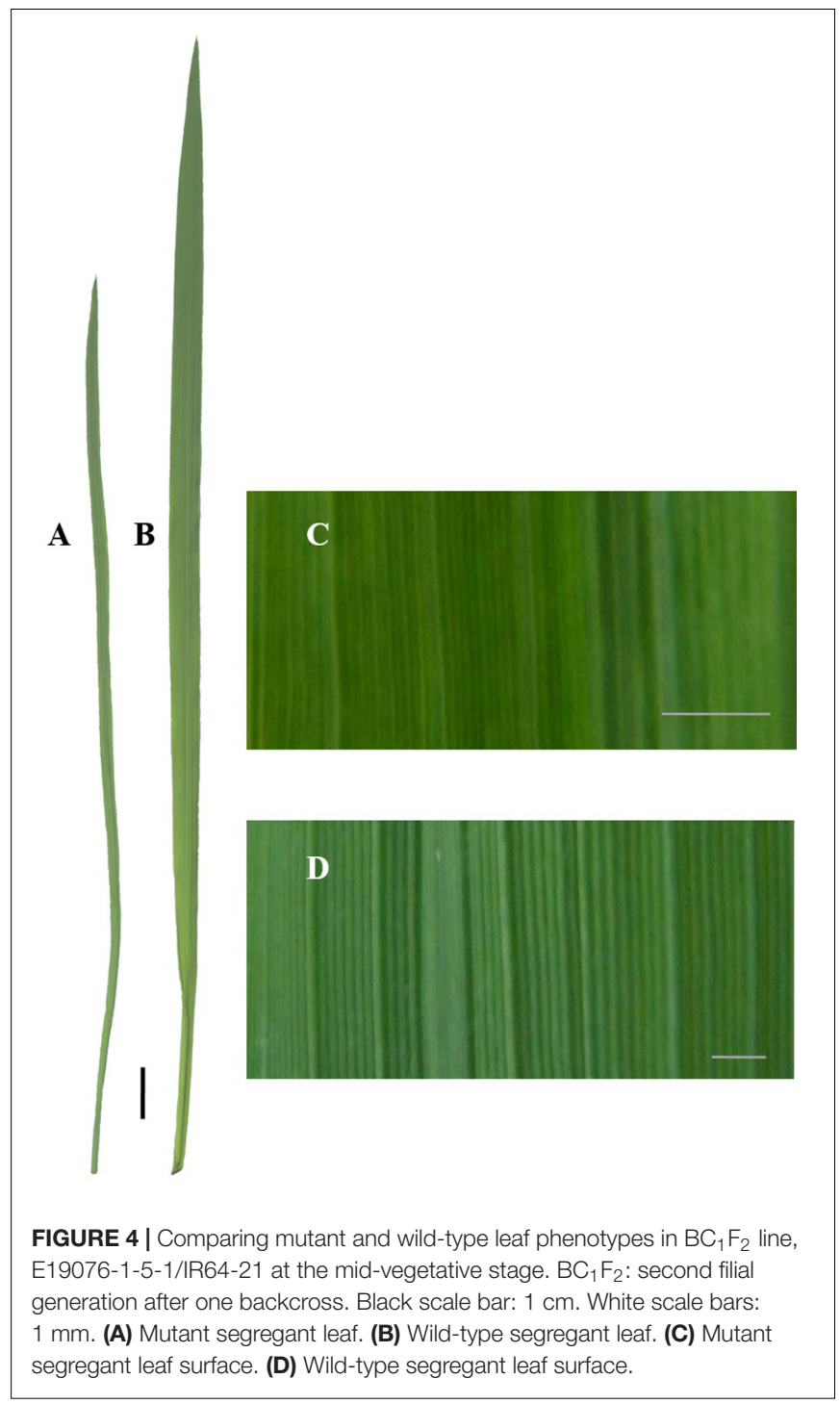

veins and the stomatal epidermis. The leaf thickness of candidate lines was generally lower ( $p<0.001$, combining all lines) than the control, even though leaf thickness varied between mutant lines $(p<0.001)$. The leaf thickness of IR64-21 had an average of $66.46 \pm 0.47 \mu \mathrm{m}$ compared to $57.43 \pm 0.66 \mu \mathrm{m}$ for E26181-1-2,
$59.71 \pm 0.69 \mu \mathrm{m}$ for E11068-1-10-1, 61.05 $\pm 0.78 \mu \mathrm{m}$ for E19076$1-5-3,62.93 \pm 0.66 \mu \mathrm{m}$ for G558-11-5-2 and $66.98 \pm 1.07 \mu \mathrm{m}$ for E22097-1-3-1.

\section{DISCUSSION}

Both the high vein density and narrow leaf width phenotypes were explained by reductions in leaf cell size without changes in interveinal cell number, in most mutant lines. However, MCs were both shorter in length and fewer in number in two of the five high vein density lines (E216181-1-1-2 and G558-11-5-2). Results showed a decrease in IVD, from 182 to as low as $134 \mu \mathrm{m}$, and in interveinal MC number, from 6.30 to as few as 5.69.

The relationship between leaf shape and anatomy deserves further attention to establish whether there is a common regulator of leaf width and vein density (Nelson and Dengler, 1997), such as the underlying anatomy or biochemical pathways [e.g., auxin (Dengler and Kang, 2001) and ethylene (Feng et al., 2015) regulation]. Leaf morphogenesis is not simply the sum of cell size and proliferation but is also affected by their interaction (Tsukaya, 2005), which is coordinated by at least three distinct mechanisms (Hisanaga et al., 2015). Various rice genotypes were shown to have a negative correlation between MC number and MC length $(p<0.005)$ (Table 1 and Supplementary Table S1). This negative correlation was also evident in Tsukaya (2002) and Tsukaya (2003). The interaction could not have been a compensation mechanism as fewer cells can trigger increases in cell size but the inverse does not exist, and so rather a form of cellcell communication is responsible for the interaction (Tsukaya, 2005). It should also be noted that the functional transition from proliferation (fixing cell number) to expansion (fixing cell size) is unidirectional and regulated by a host of genes (Kalve et al., 2014). Therefore, it may be possible that variants for decreased interveinal MC number could be modified to increase their MC sizes. It should be noted, however, that identifying rice mutants that have fewer but larger cells may be especially difficult. This is because the relatively small MC sizes of rice may be highly conserved for the reduction and recovery from photorespiration by maximizing chloroplast containing MC border surface area (Sage and Sage, 2009).

Even though the narrow leaf width phenotype was associated with the more important trait of high vein

TABLE 1 | Anatomical characteristics of $\mathrm{M}_{5}$ deletion lines.

\begin{tabular}{|c|c|c|c|c|}
\hline IR64 family & Vein no. $\left(\mathrm{mm}^{-1}\right)$ & Interveinal MC no. & MC length $(\mu \mathrm{m})$ & IVD ( $(\mu \mathrm{m})$ \\
\hline E11068-1-10-1 & $6.78 \pm 0.06^{* * *}$ & $6.85 \pm 0.21$ & $15.81 \pm 0.42^{* * *}$ & $144.40 \pm 2.50^{* * *}$ \\
\hline E19076-1-5-3 & $6.80 \pm 0.06^{* * *}$ & $5.85 \pm 0.20$ & $19.00 \pm 0.42^{* * *}$ & $152.13 \pm 5.09^{* * *}$ \\
\hline E22097-1-3-1 & $6.70 \pm 0.11^{* * *}$ & $6.12 \pm 0.17$ & $18.46 \pm 0.33^{* * *}$ & $142.14 \pm 3.07^{* * *}$ \\
\hline E26181-1-1-2 & $6.83 \pm 0.11^{* * *}$ & $5.77 \pm 0.18^{*}$ & $17.85 \pm 0.35^{* * *}$ & $134.00 \pm 2.50^{* * *}$ \\
\hline G558-11-5-2 & $6.49 \pm 0.07^{* * *}$ & $5.69 \pm 0.15^{*}$ & $18.67 \pm 0.31^{* * *}$ & $137.17 \pm 3.11^{* * *}$ \\
\hline All mutants & $6.77 \pm 0.07^{* * *}$ & $6.01 \pm 0.09$ & $18.47 \pm 0.16^{* * *}$ & $141.04 \pm 1.54^{* * *}$ \\
\hline Wild-type & $5.85 \pm 0.04$ & $6.30 \pm 0.19$ & $23.17 \pm 0.46$ & $182.00 \pm 3.87$ \\
\hline
\end{tabular}

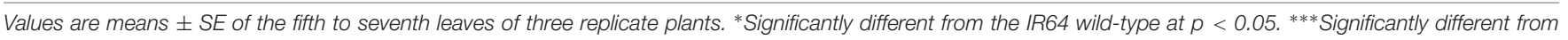
the IR64 wild-type at $p<0.001$. 


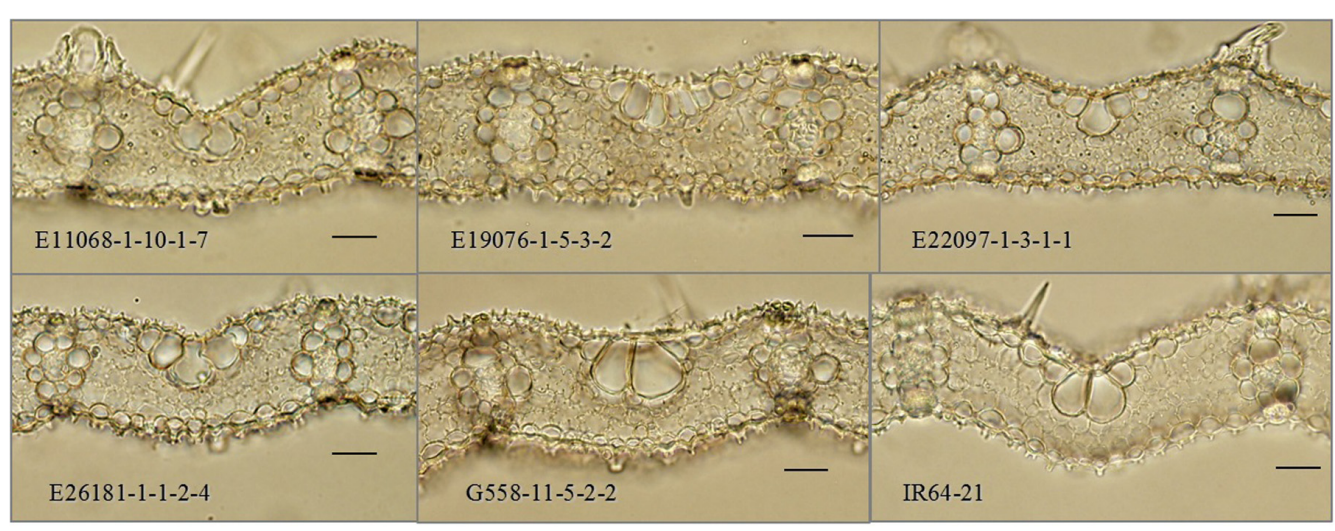

FIGURE 5 | Cross-sections of interveinal leaf areas in $M_{5}$ mutant lines. $M_{5}$ : fifth mutant generation. Black scale bars: $50 \mu \mathrm{m}$.

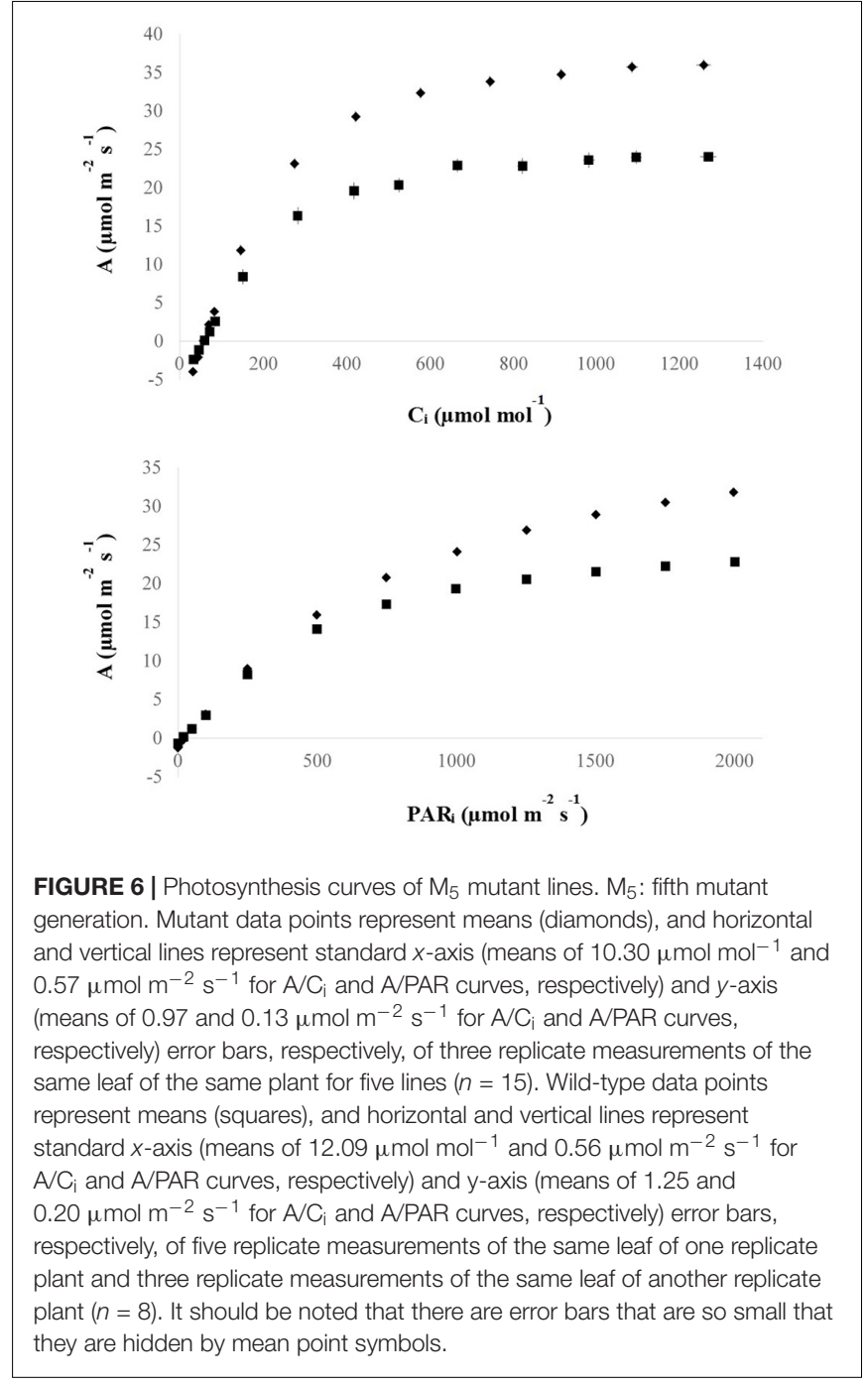

density (more specifically, a low MC:BSC ratio), it may not need to be removed from candidate lines by breeding. Having a narrow leaf width certainly was not detrimental to photosynthetic function as mutants generally outperformed their parental wild-type (Table 2, $p<0.001)$.

Photosynthesis per unit leaf area in plants is limited by a combination of prevailing factors and intrinsic leaf properties. For a leaf in optimal conditions, i.e., open stomata and saturating light, it is common for the rate of photosynthesis to be dominated by the activity of the enzyme, RuBisCO (with co-limitations by the rate of RuBP regeneration and stomatal conductance). The conductance of the leaf to $\mathrm{CO}_{2}$ and the leaf temperature are important in determining the ratio of activity of carboxylation and oxygenation within the chloroplast. Therefore, under the experimental measurement conditions, we might have expected RuBisCO activity to dominate. Our data show clearly that photosynthetic capacity per unit leaf area is higher in the mutant lines compared to the parental wild-type (Table 2, $p<0.001$ ). The increase is associated with heightened end-product capacity (TPU), RuBisCO activity (higher $\mathrm{Vc}_{\max }$ ) and electron transport capacity $\left(\mathrm{J}_{\max }\right) . V c_{\max }$ values are important since they are associated with an increase in the amount of active RuBisCO protein, an increase in the activation state of existing protein and/or an increase in the relative carboxylation activity of the existing protein per unit leaf area. Our data did not permit us to identify which mechanism dominates here, although the increased TPU and $\mathrm{Vc}_{\max }$ suggested that a combined increased capacity for both sucrose export and hydraulic conductance could be responsible (Brodribb et al., 2007; Brodribb and Feild, 2010). This would imply that the higher $\mathrm{Vc}_{\max }$ arose from an increased activation state of existing RuBisCO protein. This is associated with a slightly higher stomatal conductance and lower leaf instantaneous water use efficiency $(\mathrm{A} / \mathrm{E})$, providing evidence for enhanced hydraulic capacity. $\mathrm{g}_{\mathrm{m}}$ showed lower values in the mutant lines indicating that there was not a higher conductance for $\mathrm{CO}_{2}$.

Given that these measurements were made under saturating light, it will be important to understand how/whether this new morphology supports higher photosynthesis under 
TABLE 2 | Photosynthetic characterization of $M_{5}$ deletion candidate lines.

\begin{tabular}{|c|c|c|c|c|c|c|}
\hline & 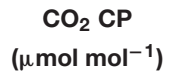 & $\begin{array}{c}V_{\mathrm{max}^{*}} \\
\left(\mu \mathrm{mol} \mathrm{m} \mathrm{m}^{-2} \mathrm{~s}^{-1}\right)\end{array}$ & $\begin{array}{c}\mathrm{J}_{\max }{ }^{* * *} \\
\left(\mu \mathrm{mol} \mathrm{m}{ }^{-2} \mathrm{~s}^{-1}\right)\end{array}$ & $\begin{array}{c}\mathrm{TPU}^{* * *} \\
\left(\mu \mathrm{mol} \mathrm{m}^{-2} \mathrm{~s}^{-1}\right)\end{array}$ & $\frac{\mathrm{gm}_{\mathrm{m}}}{\left(\mu \mathrm{mol} \mathrm{\textrm {m } ^ { - 2 }} \mathrm{s}^{-1} \mathrm{~Pa}^{-1}\right)}$ & $\begin{array}{c}\mathbf{R}_{\mathrm{d}}^{* * *} \\
\left(\mu \mathrm{mol} \mathrm{mol}^{-1}\right)\end{array}$ \\
\hline All mutants & $58.23 \pm 1.97$ & $181.41 \pm 10.83$ & $174.28 \pm 6.06$ & $13.15 \pm 0.43$ & $16.83 \pm 3.00$ & $1.12 \pm 0.08$ \\
\hline \multirow[t]{2}{*}{ Wild-type } & $54.04 \pm 2.99$ & $127.68 \pm 9.90$ & $115.91 \pm 8.41$ & $8.54 \pm 0.61$ & $19.67 \pm 4.88$ & $0.61 \pm 0.08$ \\
\hline & $\begin{array}{c}\text { QE } \\
\left(\mathrm{mol} \mathrm{mol}^{-1}\right)\end{array}$ & $\begin{array}{c}A_{\max }^{* * *} \\
\left(\mu \mathrm{mol} \mathrm{m}^{-2} \mathrm{~s}^{-1}\right)\end{array}$ & 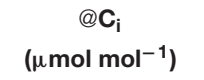 & $\begin{array}{c}@ \mathrm{gs}^{* *} \\
\left(\mathrm{~mol} \mathrm{~m}^{-2} \mathrm{~s}^{-1}\right)\end{array}$ & 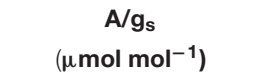 & 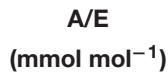 \\
\hline All mutants & $0.04 \pm 0.00$ & $31.8 \pm 1.02$ & $293.89 \pm 3.27$ & $0.74 \pm 0.03$ & $43.55 \pm 1.56$ & $2.79 \pm 0.09$ \\
\hline Wild-type & $0.04 \pm 0.00$ & $22.78 \pm 1.07$ & $292.86 \pm 4.39$ & $0.56 \pm 0.04$ & $41.91 \pm 2.86$ & $3.05 \pm 0.10$ \\
\hline
\end{tabular}

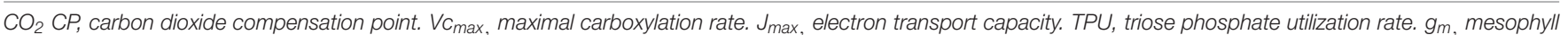

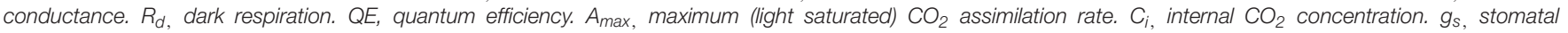

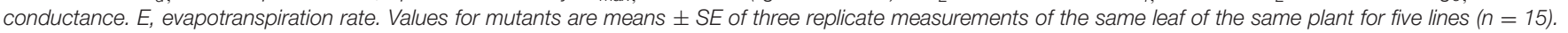

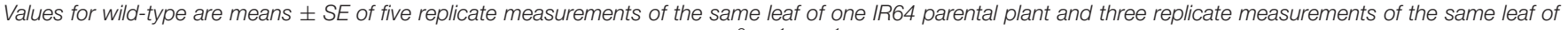

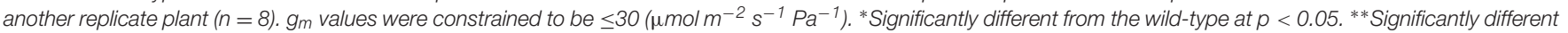

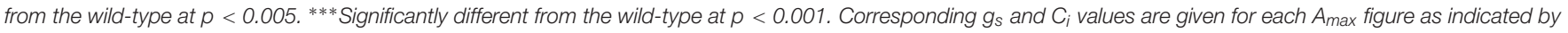
'@'. For a breakdown of photosynthetic parameters for 'all mutants' into individual lines, see Supplementary Table S2.

conditions of moderate illumination, drought and varied atmospheric humidity. Although enhanced transpiration and lowered WUE can be considered a disadvantage in conditions of lowered water availability, the need for new traits in irrigated rice that enhance biomass productivity is of higher concern.

Takai et al. (2013) linked (genetically and physiologically) photosynthetic improvement in rice to changes in both leaf morphology (leaf width, thickness and shade of green) and anatomy (mesophyll cell density). The thinner leaves in our mutant lines may be a clue to explaining their improved photosynthetic performance. This is despite thicker leaves having been correlated with traits linked to higher photosynthetic capacity, such as chlorophyll content and photosynthetic enzyme activity (Peng, 2000; Marenco et al., 2009; Takai et al., 2013), and N concentration (Murchie and Horton, 2007; Zhao et al., 2008). Two mutant lines (E11068-1-10 and E19076-1-5) had decreased SLA values in the field $(p<0.001$; results not shown and other mutant lines not measured) even though they had decreased leaf thicknesses when measured by microscopy. This was a surprising result given that the two parameters are generally closely negatively correlated (Wilson and Hattersley, 1989; Meziane and Shipley, 2001; Vile et al., 2005). The most likely explanation for the apparent inconsistency is that they had relatively high leaf weight densities, which would account for their low SLA values without the need for having thick leaves. Indeed, SLA varied with leaf density in various grasses rather than leaf thickness in Garnier and Laurent (1994), contrary to Li et al. (2005), and in fact higher leaf densities were shown to correlate with anatomical traits like a greater abundance of vascular tissue. If connecting this to the photosynthesis data, the thinner but denser leaves of mutant lines could be explained by a greater RuBisCO concentration, which would account for the increased $\mathrm{Vc}_{\max }$ values. In addition, the observation of darker green leaves of candidate lines (Figure 4C) may have indicated a greater chlorophyll content, which should be confirmed in further studies.

\section{CONCLUSION}

A previous high throughput screen identified five rice variants as having an increase in vein density, a foundational $\mathrm{C}_{4}$ photosynthesis trait (Feldman et al., 2014). These lines were shown to have other relevant traits: fewer interveinal MCs and enhanced photosynthetic rates. Therefore, given its low technology and cost, as well as its high throughput, the vein density screen could be applied to other plant species for identifying traits for the improvement of $\mathrm{C}_{3}$ photosynthesis as well as those relevant for the efforts to introduce $\mathrm{CO}_{2}$ concentrating mechanisms into rice.

\section{AVAILABILITY OF DATA AND MATERIALS}

Data supporting the article's findings, which are not in the article itself, can be requested from the corresponding author.

\section{AUTHOR CONTRIBUTIONS}

The article's authors, AF, HL, MB, AE-M, IC, WQ, JS, and EM made substantial contributions to the conception or design of the work (AF, HL, WQ, JS, and EM); or the acquisition (AF, MB, AE-M, and IC), analysis (AF, HL, and EM), or interpretation of data for the work (AF, HL, WQ, JS, and EM); and drafting the work or revising it critically for important intellectual content; and final approval of the version to be published; and agreement to be accountable for all aspects of the work in ensuring that questions related to the accuracy or integrity of any part of the work are appropriately investigated and resolved.

\section{FUNDING}

This work was supported by the Biotechnology and Biological Sciences Research Council [grant number BB/JOO3999/1]; this 
work was also coordinated and partially funded by the $\mathrm{C}_{4}$ Rice Project (http://c4rice.irri.org), and the Monsanto BeachellBorlaug International Scholars Program.

\section{ACKNOWLEDGMENTS}

Researcher support from IRRI, apart from those in the author list, especially came from the Genetics Laboratory and the $\mathrm{C}_{4}$

\section{REFERENCES}

Boyce, C. K., Brodribb, T. J., Feild, T. S., and Zwieniecki, M. A. (2009). Angiosperm leaf vein evolution was physiologically and environmentally transformative. Proc. R. Soc. Biol. Sci. 276, 1771-1776. doi: 10.1098/rspb.2008.1919

Brodribb, T. J., and Feild, T. S. (2010). Leaf hydraulic evolution led a surge in leaf photosynthetic capacity during early angiosperm diversification. Ecol. Lett. 13, 175-183. doi: 10.1111/j.1461-0248.2009.01410.x

Brodribb, T. J., Feild, T. S., and Jordan, G. J. (2007). Leaf maximum photosynthetic rate and venation are linked by hydraulics. Plant Physiol. 144, 1890-1898. doi: 10.1104/pp.107.101352

Challinor, A. J., Watson, J., Lobell, D. B., Howden, S. M., Smith, D. R., and Chhetri, N. (2014). A meta-analysis of crop yield under climate change and adaptation. Nat. Climate Change 4, 287-291. doi: 10.1038/nature13809

Christin, P. A., Osborne, C. P., Chatelet, D. S., Columbus, J. T., Besnard, G., Hodkinson, T. R., et al. (2013). Anatomical enablers and the evolution of $\mathrm{C}_{4}$ photosynthesis in grasses. Proc. Natl. Acad. Sci. U.S.A. 110, 1381-1386. doi: $10.1073 /$ pnas. 1216777110

Covshoff, S., Szecowka, M., Hughes, T. E., Smith-Unna, R., Kelly, S., Bailey, K. J., et al. (2016). $\mathrm{C}_{4}$ Photosynthesis in the rice paddy: insights from the noxious weed Echinochloa glabrescens. Plant Physiol. 170, 57-73. doi: 10.1104/pp.15. 00889

Dengler, N. G., Dengler, R. E., Donnelly, P. M., and Hattersley, P. W. (1994). Quantitative leaf anatomy of C3 and C4 grasses (Poaceae): bundle sheath and mesophyll surface area relationships. Ann. Bot. 73, 241-255. doi: 10.1006/anbo. 1994.1029

Dengler, N. G., and Kang, J. (2001). Vascular patterning and leaf shape. Curr. Opin. Plant Biol. 4, 50-56. doi: 10.1016/S1369-5266(00)00135-7

Feldman, A. B., Murchie, E. H., Leung, H., Baraoidan, M., Coe, R., Yu, S.-M., et al. (2014). Increasing leaf vein density by mutagenesis: laying the foundations for $\mathrm{C}_{4}$ rice. PLOS ONE 9:e94947. doi: 10.1371/journal.pone.0094947

Feng, G., Liu, G., and Xiao, J. (2015). The Arabidopsis EIN2 restricts organ growth by retarding cell expansion. Plant Signal. Behav. 10:e1017169. doi: 10.1080/ 15592324.2015.1017169

Garnier, E., and Laurent, G. (1994). Leaf anatomy, specific mass and water content in congeneric annual and perennial grass species. New Phytol. 128, 725-736. doi: 10.1111/j.1469-8137.1994.tb04036.x

Giuliani, R., Koteyeva, N., Voznesenskaya, E., Evans, M. A., Cousins, A. B., and Edwards, G. E. (2013). Coordination of leaf photosynthesis, transpiration, and structural traits in rice and wild relatives (genus Oryza). Plant Physiol. 162, 1632-1651. doi: 10.1104/pp.113.217497

Hisanaga, T., Kawade, K., and Tsukaya, H. (2015). Compensation: a key to clarifying the organ-level regulation of lateral organ size in plants. J. Exp. Bot. 66, 1055-1063. doi: 10.1093/jxb/erv028

Kajala, K., Covshoff, S., Karki, S., Woodfield, H., Tolley, B. J., Dionora, M., et al. (2011). Strategies for engineering a two-celled C4 photosynthetic pathway into rice. J. Exp. Bot. 62, 3001-3010. doi: 10.1093/jxb/err022

Kalve, S., De Vos, D., and Beemster, G. T. S. (2014). Leaf development: a cellular perspective. Front. Plant Sci. 5:362. doi: 10.3389/fpls.2014.00362

Karki, S., Rizal, G., and Quick, W. (2013). Improvement of photosynthesis in rice (Oryza sativa L.) by inserting the C4 pathway. Rice 6:28. doi: 10.1186/19398433-6-28

Kromdijk, J., Głowacka, K., Leonelli, L., Gabilly, S. T., Iwai, M., Niyogi, K. K., et al. (2016). Improving photosynthesis and crop productivity by accelerating recovery from photoprotection. Science 354, 857-861. doi: 10.1126/science. aai 8878
Rice Center Transgenic Physiology team, including individuals like Pedro Reaño and Robert Coe.

\section{SUPPLEMENTARY MATERIAL}

The Supplementary Material for this article can be found online at: https://www.frontiersin.org/articles/10.3389/fpls.2017.01883/ full\#supplementary-material

Leegood, R. C. (2000). "Overcoming barriers: CO2-concentrating mechanisms and C4 metabolism in relation to transport," in Redesigning Rice Photosynthesis to Increase Yields, eds J. E. Sheehy, P. L. Mitchell, and B. Hardy (Amsterdam: Elsevier Science B.V).

Li, Y., Johnson, D. A., Su, Y., Cui, J., and Zhang, T. (2005). Specific leaf area and leaf dry matter content of plants growing in sand dunes. Bot. Bull. Acad. Sin. 46, 127-134.

Long, S. P., Zhu, X.-G., Naidu, S. L., and Ort, D. R. (2006). Can improvement in photosynthesis increase crop yields? Plant Cell Environ. 29, 315-330.

Marenco, R. A., Antezana-Vera, S. A., and Nascimento, H. S. C. (2009). Relationship between specific leaf area, leaf thickness, leaf water content and SPAD-502 readings in six Amazonian tree species. Photosynthetica 47, 184-190. doi: 10.1007/s11099-009-0031-6

McElrone, A. J., Choat, B., Gambetta, G. A., and Brodersen, C. R. (2013). Water uptake and transport in vascular plants. Nat. Educ. Knowl. 4:6.

McKown, A. D., and Dengler, N. G. (2007). Key innovations in the evolution of Kranz anatomy and $\mathrm{C}_{4}$ vein pattern in Flaveria (Asteraceae). Am. J. Bot. 94, 382-399. doi: 10.3732/ajb.94.3.382

McKown, A. D., and Dengler, N. G. (2009). Shifts in leaf vein density through accelerated vein formation in C4 Flaveria (Asteraceae). Ann. Bot. 104, 1085-1098. doi: 10.1093/aob/mcp210

Meziane, D., and Shipley, B. (2001). Direct and indirect relationships between specific leaf area, leaf nitrogen and leaf gas exchange. Effects of irradiance and nutrient supply. Ann. Bot. 88, 915-927. doi: 10.1006/anbo.2001. 1536

Mitchell, P. L., and Sheehy, J. E. (2006). Supercharging rice photosynthesis to increase yield. New Phytol. 171, 688-693. doi: 10.1111/j.1469-8137.2006. 01855.x

Murchie, E. H., and Horton, P. (2007). "Toward C4 rice: learning from the acclimation of photosynthesis in the C3 leaf," in Charting New Pathways to C4 Rice, eds J. E. Sheehy, P. L. Mitchell, and B. Hardy (Los Baòos, CA: International Rice Research Institute).

Murchie, E. H., and Niyogi, K. K. (2011). Manipulation of photoprotection to improve plant photosynthesis. Plant Physiol. 155, 86-92. doi: 10.1104/pp.110. 168831

Murchie, E. H., Pinto, M., and Horton, P. (2009). Agriculture and the new challenges for photosynthesis research. New Phytol. 181, 532-552. doi: 10.1111/ j.1469-8137.2008.02705.x

Nardini, A., Salleo, S., and Raimondo, F. (2003). Changes in leaf hydraulic conductance correlate with leaf vein embolism in Cercis siliquastrum L. Trees Struct. Funct. 17, 529-534. doi: 10.1007/s00468-003-0265-z

Nelson, T., and Dengler, N. G. (1997). Leaf vascular pattern formation. Plant Cell 9, 1121-1135. doi: 10.1105/tpc.9.7.1121

Ort, D. R., Merchant, S. S., Alric, J., Barkan, A., Blankenship, R. E., Bock, R., et al. (2015). Redesigning photosynthesis to sustainably meet global food and bioenergy demand. Proc. Natl. Acad. Sci. U.S.A. 112, 8529-8536. doi: 10.1073/ pnas. 1424031112

Peng, S. (2000). "Single-leaf and canopy photosynthesis of rice," in Redesigning Rice Photosynthesis to Increase Yields, eds J. E. Sheehy, P. L. Mitchell, and B. Hardy (Amsterdam: Elsevier Science B.V).

Ray, D. K., Ramankutty, N., Mueller, N. D., West, P. C., and Foley, J. A. (2012). Recent patterns of crop yield growth and stagnation. Nat. Commun. 3:1293. doi: $10.1038 /$ ncomms 2296

Rishmawi, L., Bühler, J., Jaegle, B., Hülskamp, M., and Koornneef, M. (2017). Quantitative trait loci controlling leaf venation in Arabidopsis. Plant Cell Environ. 40, 1429-1441. doi: 10.1111/pce.12938 
Sack, L., and Scoffoni, C. (2013). Leaf venation: structure, function, development, evolution, ecology and applications in the past, present and future. New Phytol. 198, 983-1000. doi: 10.1111/nph.12253

Sage, T. L., and Sage, R. F. (2009). The functional anatomy of rice leaves: implications for refixation of photorespiratory $\mathrm{CO} 2$ and efforts to engineer C4 photosynthesis into rice. Plant Cell Physiol. 50, 756-772. doi: 10.1093/pcp/ pcp033

Scoffoni, C., Rawls, M., McKown, A., Cochard, H., and Sack, L. (2011). Decline of leaf hydraulic conductance with dehydration: relationship to leaf size and venation architecture. Plant Physiol. 156, 832-843. doi: 10.1104/pp.111. 173856

Sharkey, T. D., Bernacchi, C. J., Farquhar, G. D., and Singsaas, E. L. (2007). Fitting photosynthetic carbon dioxide response curves for C3 leaves. Plant Cell Environ. 30, 1035-1040. doi: 10.1111/j.1365-3040.2007. 01710.x

Takai, T., Adachi, S., Taguchi-Shiobara, F., Sanoh-Arai, Y., Iwasawa, N., Yoshinaga, S., et al. (2013). A natural variant of NAL1, selected in high-yield rice breeding programs, pleiotropically increases photosynthesis rate. Sci. Rep. 3:2149. doi: 10.1038/srep02149

Taylaran, R. D., Adachi, S., Ookawa, T., Usuda, H., and Hirasawa, T. (2011). Hydraulic conductance as well as nitrogen accumulation plays a role in the higher rate of leaf photosynthesis of the most productive variety of rice in Japan. J. Exp. Bot. 62, 4067-4077. doi: 10.1093/jxb/err126

Tsukaya, H. (2002). Interpretation of mutants in leaf morphology: genetic evidence for a compensatory system in leaf morphogenesis that provides a new link between Cell and organismal theory. Int. Rev. Cytol. 217, 1-39. doi: 10.1016/ S0074-7696(02)17011-2

Tsukaya, H. (2003). Organ shape and size: a lesson from studies of leaf morphogenesis. Curr. Opin. Plant Biol. 6, 57-62. doi: 10.1016/S1369 526602000055

Tsukaya, H. (2005). Leaf shape: genetic controls and environmental factors. Int. J. Dev. Biol. 49, 547-555. doi: 10.1387/ijdb.041921ht
Vile, D., Garnier, E., Shipley, B., Laurent, G., Navas, M.-L., Roumet, C., et al. (2005). Specific leaf area and dry matter content estimate thickness in laminar leaves. Ann. Bot. 96, 1129-1136. doi: 10.1093/aob/mci264

Wilson, J. R., and Hattersley, P. W. (1989). Anatomical characters and digestibility of leaves of Panicum and other grass genera with $\mathrm{C}_{3}$ and different types of $\mathrm{C}_{4}$ photosynthetic pathway. Austr. J. Agric. Res. 40, 125-136. doi: 10.1071/ AR9890125

Wu, J.-L., Wu, C., Lei, C., Baraoidan, M., Bordeos, A., Madamba, M., et al. (2005). Chemical- and irradiation-induced mutants of indica rice IR64 for forward and reverse genetics. Plant Mol. Biol. 59, 85-97. doi: 10.1007/s11103-004-5112-0

Zhao, M., Lafitte, H. R., Sacks, E., Dimayuga, G., and Acuña, T. L. B. (2008) Perennial O. sativa x O. rufipogon interspecific hybrids: I. Photosynthetic characteristics and their inheritance. Field Crops Res. 106, 203-213. doi: 10.1016/j.fcr.2007.12.005

Zhu, X.-G., Long, S. P., and Ort, D. R. (2010). Improving photosynthetic efficiency for greater yield. Annu. Rev. Plant Biol. 61, 235-261. doi: 10.1146/annurevarplant-042809-112206

Conflict of Interest Statement: The authors declare that the research was conducted in the absence of any commercial or financial relationships that could be construed as a potential conflict of interest.

The reviewer RSC declared a shared affiliation with one of the authors, WQ, to the handling Editor.

Copyright (c) 2017 Feldman, Leung, Baraoidan, Elmido-Mabilangan, Canicosa, Quick, Sheehy and Murchie. This is an open-access article distributed under the terms of the Creative Commons Attribution License (CC BY). The use, distribution or reproduction in other forums is permitted, provided the original author(s) or licensor are credited and that the original publication in this journal is cited, in accordance with accepted academic practice. No use, distribution or reproduction is permitted which does not comply with these terms. 